\title{
Wideband electromagnetically coupled coaxial probe fed slot loaded stacked patch antenna
}

\author{
D.K. Srivastava ${ }^{1}$, J.P. Saini ${ }^{1}$, D.S. Chauhan ${ }^{2}$ \\ ${ }^{1 *}$ Department of Electronics and Communication Engineering, BIET Jhansi, INDIA \\ ${ }^{2}$ Uttarakhand Technical University, Dehradun, INDIA \\ ${ }^{*}$ Corresponding Author: e-mail: dks1_biet@rediffmail.com, Tel +91-512-2597009, Fax.+91-9415179133
}

\begin{abstract}
A wideband U-slot loaded rectangular patch stacked with horizontal slot loaded rectangular patch antenna is presented in this paper. The resonating behavior of antenna depends on slot width, slot length of side arm and base arm of U-slot. Similarly, it depends on separation between the two patches. Optimization of these parameters gives impedance Bandwidth of 54.6\%.
\end{abstract}

Keywords: U-slot, Rectangular, stacked and wideband antenna.

\section{Introduction}

Microstrip antenna exhibits narrow bandwidth and low gain that limits its application in practice (Bahl et al, 1980 and Balanis, 1997). Several approaches have been made to improve the bandwidth of the patch antenna, such as use of a thick or foam substrate, cutting slots or notches like U-slot, E-shaped, H-shaped patch antennas and two layer electromagnetically coupled stacked structures (Ansari and Ram, 2008; Bafrooei et al, 1999; Ansari, Ram and Singh, 2008; Chen et al, 1984; Ansari, Singh and Dubey, 2008; Svacina, 1992; Ansari and Ram, 2008; Kumar et al, 1984 and Sabban, 1983). Several dual frequency and wide band antennas have been reported using stacked structures. A U-slot loaded rectangular patch stacked with H-shaped parasitic patch exhibits dual band (Ansari, Singh and Dubey, 2008). Electromagnetically coupled U-slot loaded rectangular patch stacked with rectangular patch yields wideband. The theoretical analysis for the antenna structure is carried out using equivalent circuit model (Hoefer, 1997; Balanis, 1997; Bahl et al, 1980 and Bahl, 2003) and is simulated using IE3D simulation software.

\section{Theoretical Considerations}

The antenna structure is shown in figure 1. The upper parasitic layer is horizontal slot loaded rectangular patch and lower one is coaxial probe fed U-slot loaded patch. Due to presence of parasitic element in the stacked configuration, there are two resonant associated with two resonators. These two resonance frequencies are closely spaced to give broadband characteristics. Current distribution in upper and lower patches at both the resonance frequencies is shown in figure 2 for the antenna structure simulated using IE3D simulation software. The first resonator is considered as a microstrip patch with dielectric cover which causes a change in resonance frequency and effective dielectric constant. Microstrip patch with a dielectric cover is considered as a single patch with a semi-infinite superstrate with relative permittivity equal unity and single relative dielectric constant $\left(\varepsilon_{\mathrm{s}}\right)$ given as (Svacina, 1992) -

$$
\varepsilon_{s}=\frac{2 \varepsilon_{f f}-1+p}{1+p} \quad \text { Where, } p=1+\frac{10 h_{1}}{W_{1 e}}
$$

In which $\mathrm{W}_{\mathrm{ie}}$ is effective width and $\varepsilon_{\mathrm{ff}}$ is effective dielectric constant of structure, $\mathrm{h}_{1}$ is height between ground plane and lower patch. $\mathrm{W}_{1}$ is the width of the patch. A simple rectangular microstrip antenna is considered as a parallel combination of Resistance $\left(\mathrm{R}_{1}\right)$, inductance $\left(\mathrm{L}_{1}\right)$ and capacitance $\left(\mathrm{C}_{1}\right)$, the values of which can be defined as (Bahl et al, 1980). 


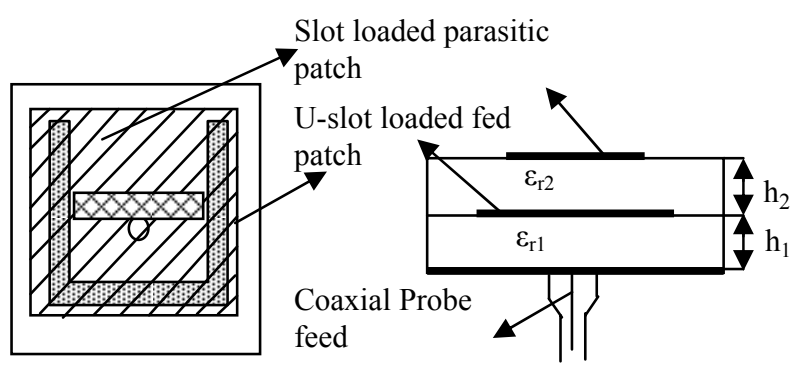

(a)

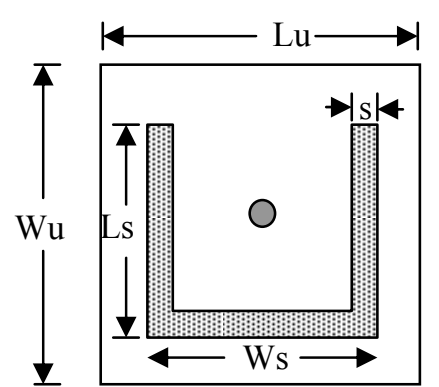

(b)

Figure 1. (a) Top and side view of antenna (b) U-slot loaded lower patch and slot loaded rectangular upper patch

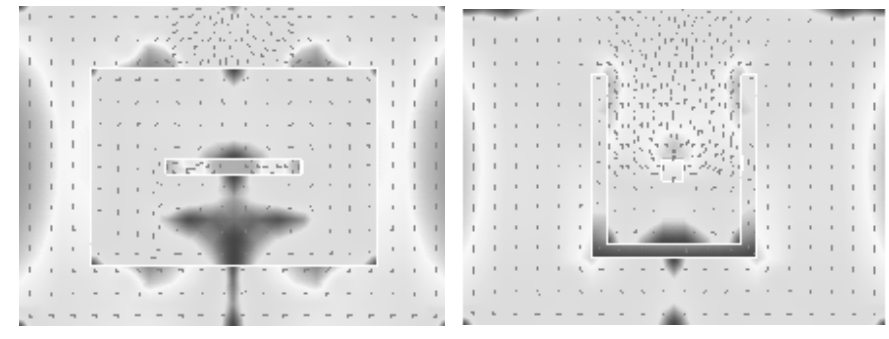

(a)
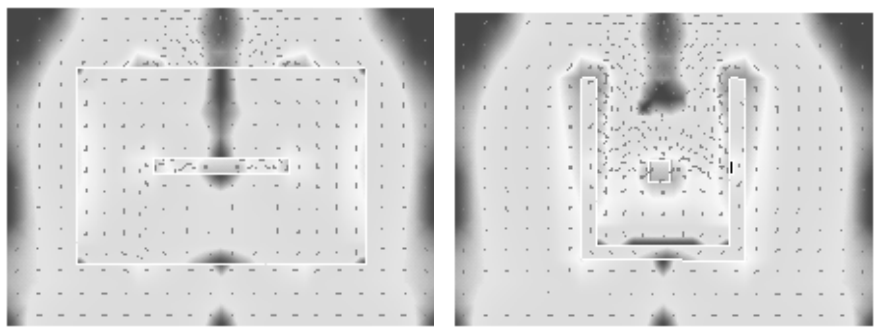

(b)

Figure 2. Current distribution in upper and lower patches at (a) lower resonance frequency and (b) upper resonance frequency

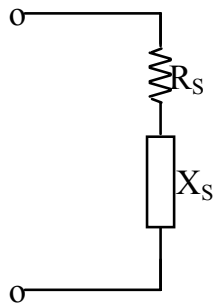

(a)

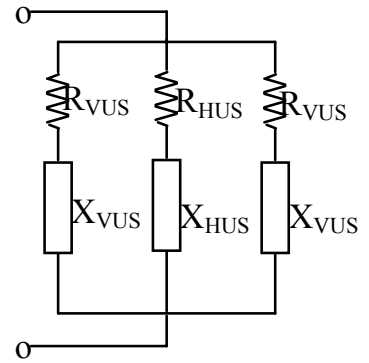

(b)

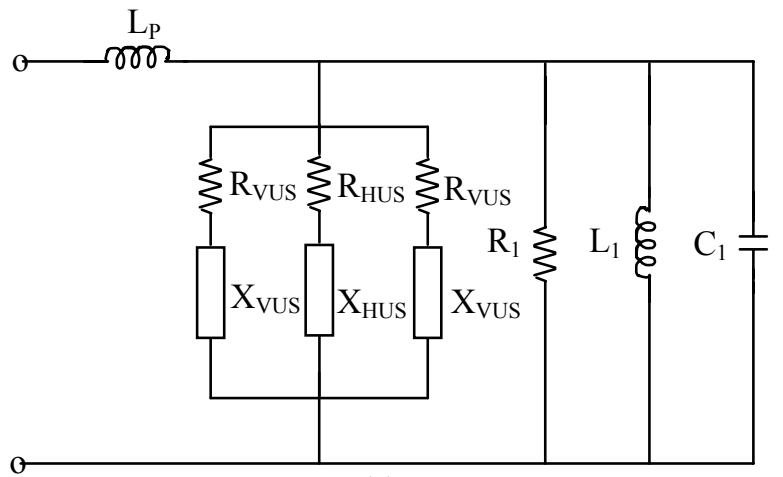

(c)

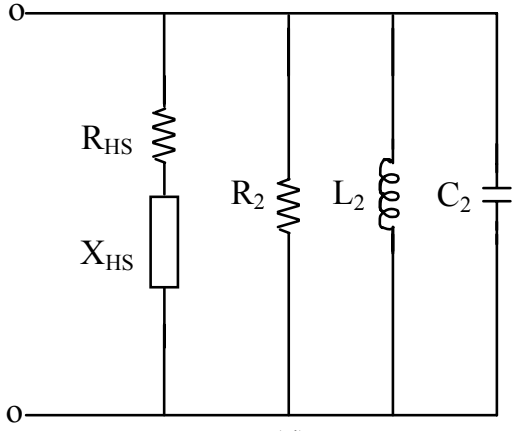

(d)

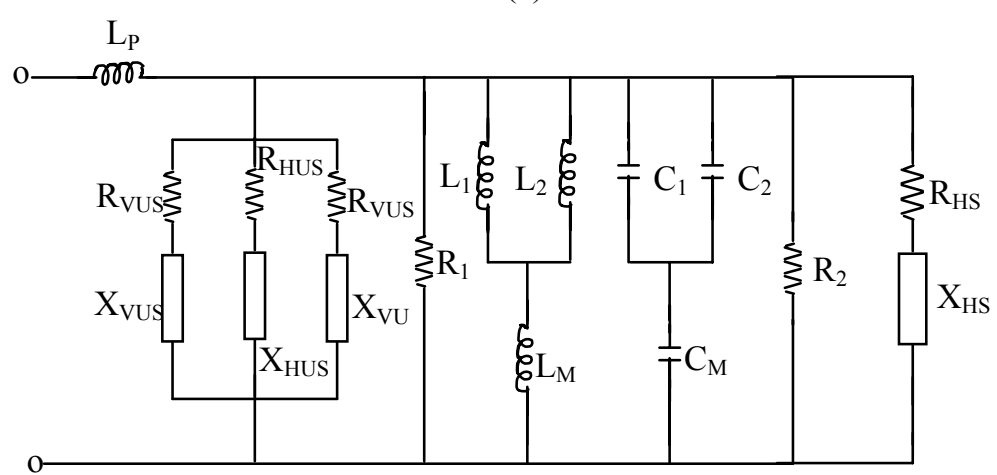

(e)

Figure 3. Equivalent circuit of (a) a narrow slot (b) U- shaped slot (c) U- shaped slot loaded lower patch fed with coaxial probe (d) slot loaded upper rectangular patch and (e) proposed stacked patch antenna. 
Slot can be analyzed by using duality relationship between the dipole and the slot. Figure 3(a) shows the equivalent circuit of narrow slot. The U-shape slot cut in lower patch is thin and considered as combination of three slots i.e. two parallel to radiating edge and the third one perpendicular to the radiating edge. Thus, $Z_{\mathrm{VUS}}$ and $\mathrm{Z}_{\mathrm{HUS}}$ can be evaluated by considering single narrow slot and can be combined as shown in figure 3(b) to give the impedance of U-slot. Figure 3(c) represents equivalent circuit of U-slot loaded rectangular patch. Figure 3(d) represents equivalent circuit of single horizontal slot loaded rectangular upper patch. The equivalent circuit of proposed antenna structure is shown in figure 2(e). The equivalent circuit of a narrow slot shown in figure 3 (a) comprises of a series combination of the radiation resistance $\left(R_{s}\right)$ and the reactive component $\left(X_{s}\right)$ (Ansari and Ram, 2008).

Thus, the impedance of a single slot can be written as -

$$
Z_{s}=R_{s}\left(k_{o} \ell\right)+j X_{s}\left(k_{o} \ell\right)
$$

Where, $\mathrm{R}_{\mathrm{s}}\left(\mathrm{k}_{\mathrm{o}} \ell\right)$ and $\mathrm{X}_{\mathrm{s}}\left(\mathrm{k}_{\mathrm{o}} \ell\right)$ are given as -

$R_{S}=60\left\{C+\ln \left(k_{o} \ell\right)-C_{i}\left(k_{o} \ell\right)+\frac{1}{2} \sin \left(k_{o} \ell\right)\left[S_{i}\left(2 k_{o} \ell\right)-2 S_{i}\left(k_{o} \ell\right)\right]+\frac{1}{2} \cos \left(k_{o} \ell\right)\left[C+\ln \left(\frac{k_{o} \ell}{2}\right)+C_{i}\left(2 k_{o} l\right)-2 C_{i}\left(k_{o} l\right)\right]\right\} \cos \psi$

And, $\quad X_{S}=30\left\{2 S_{i}\left(k_{o} l\right) \cos \left(k_{o} l\right)\left[2 S_{i}\left(k_{o} l\right)-S_{i}\left(2 k_{o} l\right)\right]-\sin \left(k_{o} l\right)\left[2 C_{i}\left(k_{o} l\right)-C_{i}\left(2 k_{o} l\right)-C_{i}\left(\frac{2 k_{o} s^{2}}{\ell}\right)\right]\right\}$

Where, $k_{o}=\frac{2 \pi}{\lambda}$ (wave vector), $\ell$ is length of slot, $\mathrm{s}$ is width of slot, $\mathrm{C}=0.5772$ and $\psi$ is the inclination of the slot from the radiating edge. $S_{i}(k \ell)$ and $C_{i}(k \ell)$ are the sine and cosine integral given as -

$$
S_{i}(x)=\int_{0}^{x} \frac{\sin (x)}{x} d x \text { and } C_{i}(x)=-\int_{x}^{\infty} \frac{\sin (x)}{x} d x
$$

The U-shape slot cut in lower patch is thin and considered as three slots i.e. two slots parallel to the radiating edge and the third one perpendicular to the radiating edge. Thus, $Z_{\mathrm{VUS}}$ (Impedance of Vertical arm in U-slot) and $Z_{\mathrm{HUS}}$ (Impedance of horizontal arm in U-slot) can be evaluated by considering single narrow slot. Now, these can be combined as shown in figure 2(b) to give the impedance of U-slot. Thus, impedance of the U-slot in lower patch can be given as -

$$
Z_{U S}=\frac{Z_{V U S}+2 Z_{H U S}}{Z_{V U S} Z_{H U S}}
$$

The equivalent circuit of rectangular patch stacked with U-slot loaded fed patch can be represented as shown in figure 2(e). Thus, Total impedance of antenna structure can be given as -

$$
Z_{T}=j w L_{p}+\frac{1}{\frac{1}{Z_{U S}}+\frac{1}{R_{3}}+j w C_{3}+\frac{1}{j w L_{3}}+\frac{1}{Z_{H S}}}
$$

Where, $R_{3}=\frac{R_{1} R_{2}}{R_{1}+R_{2}}, L_{3}=L_{M}+\frac{L_{1} L_{2}}{L_{1}+L_{2}}$ and $\quad C_{3}=\frac{\left(C_{1}+C_{2}\right) C_{M}}{C_{1}+C_{2}+C_{M}}$

And similarly $\mathrm{Z}_{\mathrm{HS}}$, Impedance of horizontal slot in upper rectangular patch can be evaluated by considering single narrow slot as before. $\mathrm{R}_{2}, \mathrm{~L}_{2}$ and $\mathrm{C}_{2}$ represents the parallel combination of upper rectangular patch without slot and are evaluated as for lower patch. $L_{p}$ is the probe inductance (Ansari and Ram, 2008). $L_{M}$ and $C_{M}$ are mutual inductance capacitance due to electromagnetic coupling between the two patches, given as (Ansari, Ram and Singh, 2008)-

Reflection coefficient $(\rho)$ of the antenna can be given as (Bahl et al, 1980) -

$$
(\Gamma)=\frac{Z_{T}-Z_{o}}{Z_{T}+Z_{0}}
$$

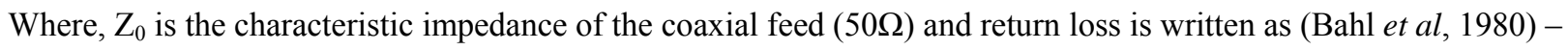

$$
R L=20 \log |\Gamma|
$$

Since the parasitic patch is mounted directly on the fed patch, therefore the two patches can be considered in same phase. Thus, the radiation field for the proposed antenna for far field radiation can be written as (Ansari and Ram, 2008 and Balanis, 1997).

\section{Design Specifications}

The design parameters for the stacked structure under consideration (Ansari, Singh and Dubey, 2008) are optimized for good excitation over entire range of operation. The length of lower patch $\left(\mathrm{L}_{\mathrm{U}}\right)$ is $39.4 \mathrm{~mm}$ and width $\left(\mathrm{W}_{\mathrm{U}}\right)$ is $29.4 \mathrm{~mm}$. The length of the base arm of $U$-slot $\left(\mathrm{W}_{\mathrm{s}}\right)$ is $12.5 \mathrm{~mm}$ and length of the side arm of $\mathrm{U}$-slot $\left(\mathrm{L}_{\mathrm{s}}\right)$ is $17.0 \mathrm{~mm}$. Width of the of slot (s) is $1.4 \mathrm{~mm}$. The 
length of upper rectangular patch $\left(\mathrm{L}_{\mathrm{r}}\right)$ is $26.5 \mathrm{~mm}$ and width $\left(\mathrm{W}_{\mathrm{r}}\right)$ is $18.0 \mathrm{~mm}$. The length of the horizontal slot $\left(\mathrm{L}_{\mathrm{hs}}\right)$ is $12.5 \mathrm{~mm}$ and width of the of slot $\left(\mathrm{W}_{\mathrm{hs}}\right)$ is $1.4 \mathrm{~mm}$. The two patches are stacked and aligned along a centre axis. The dielectric constant of lower layer $\left(\epsilon_{1}\right)$ is 1.1 and upper layer $\left(\epsilon_{2}\right)$ is 1.01 . The thickness of the bottom dielectric layer $(\mathrm{h} 1)$ is $6.0 \mathrm{~mm}$ and upper dielectric layer (h2) is $5.5 \mathrm{~mm}$. The feeding patch is located near the centre of lower patch for good excitation.

\section{Results and Discussions}

The U-slot loaded rectangular patch stacked with rectangular patch as shown in figure 1. The lower U-slot patch is fed with coaxial probe and upper parasitic patch is electromagnetically coupled. The structure is simuated using IE3D simulation software and theoretically investigated using equivalent circuit cavity model. Variation of return loss with frequency is shown for different slot dimensions in lower and thicknesses of the patches. It is observed that the two resonances at $3.65 \mathrm{GHz}$ and $4.66 \mathrm{GHz}$ are closely spaced to exhibit wide band of $54.6 \%$ impedance band width for simulated antenna structure. Figure 4(a) displays the theoretical and simulation results which are in close agreement. Figure 4(b) shows that both the resonance frequencies are shifted to higher side and impedance improves at both the resonances with decreases in width of U-slot in lower patch. It is observed from figure 4(c) that with increase in side length of the U-slot in lower patch, there is slight shift in upper resonance with improved matching and very little shift in lower resonance is seen while matching improves with decrease in side length of U-slot at lower resonance. Figure 4(d) depicts the slight shift in both the resonances, with change in length of base arm of U-slot in lower patch and impedance improves more in lower resonance than higher resonance with decrease in length of base arm of U-slot. There is slight shift in both the resonances with change in thickness of lower dielectric layer and impedance improves at lower resonance with increase in thickness of lower dielectric layer as is seen from Figure 4(e). It is observed from Figure 4(f) that the $3 \mathrm{~dB}$ beamwidths are approximately $68^{\circ}$ and $66^{\circ}$ for lower and upper resonances respectively. It is obsreved that the antenna displays the same radiation pattern and radiation characteristics for the entire band.

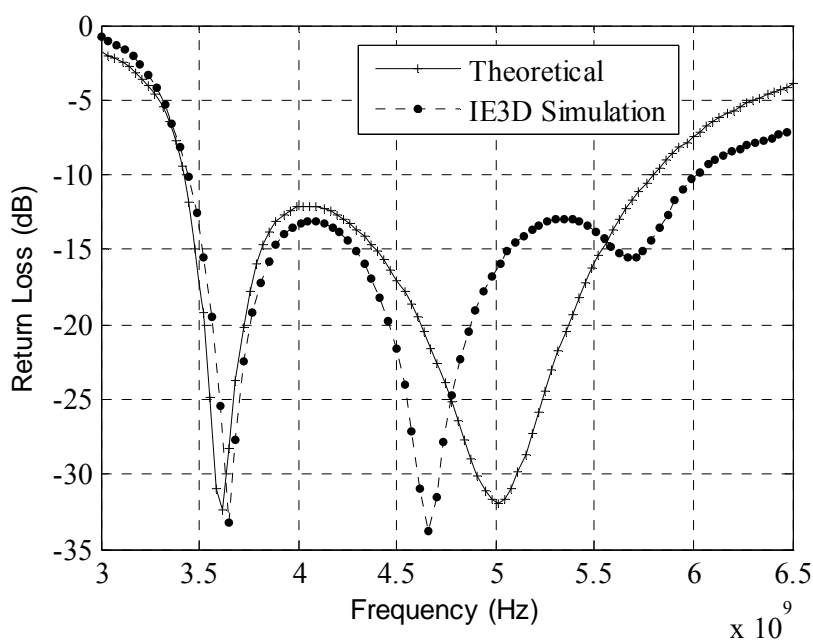

(a)

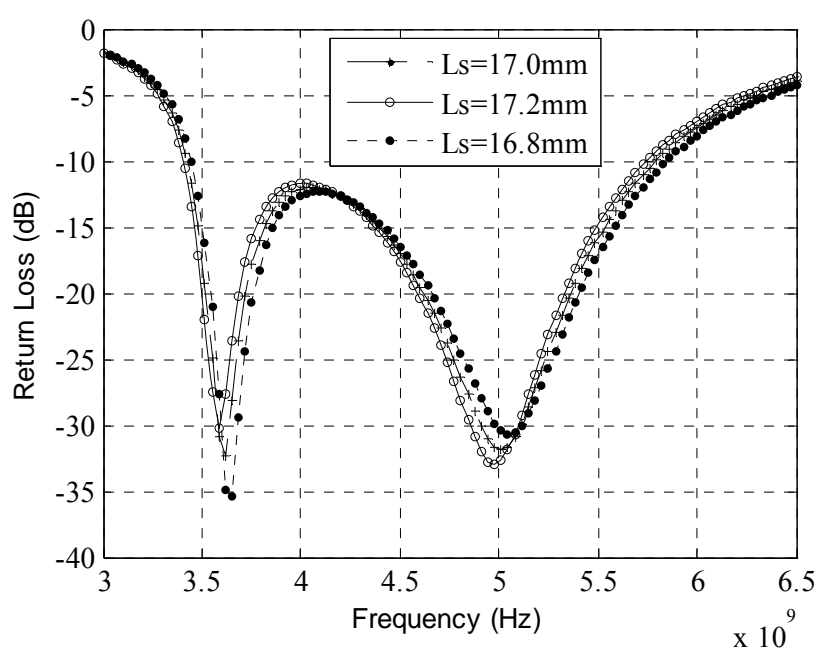

(c)

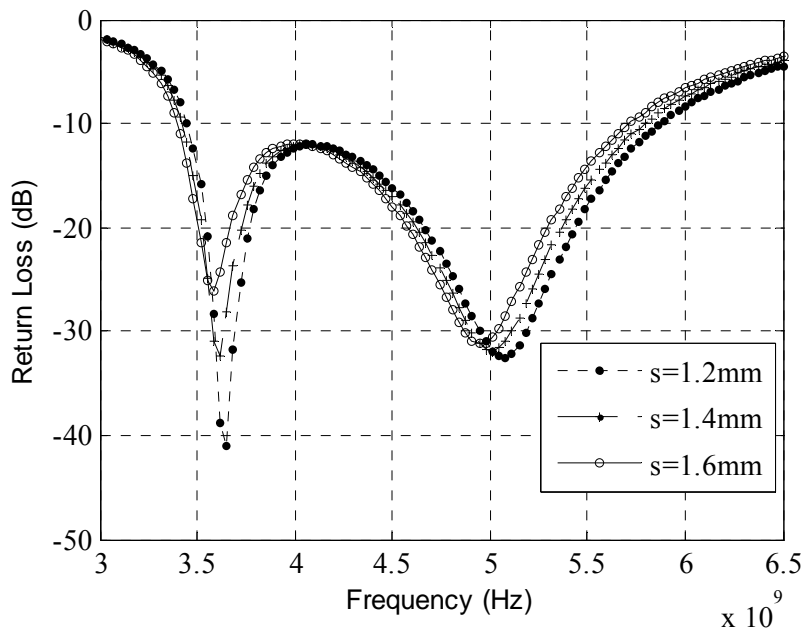

(b)

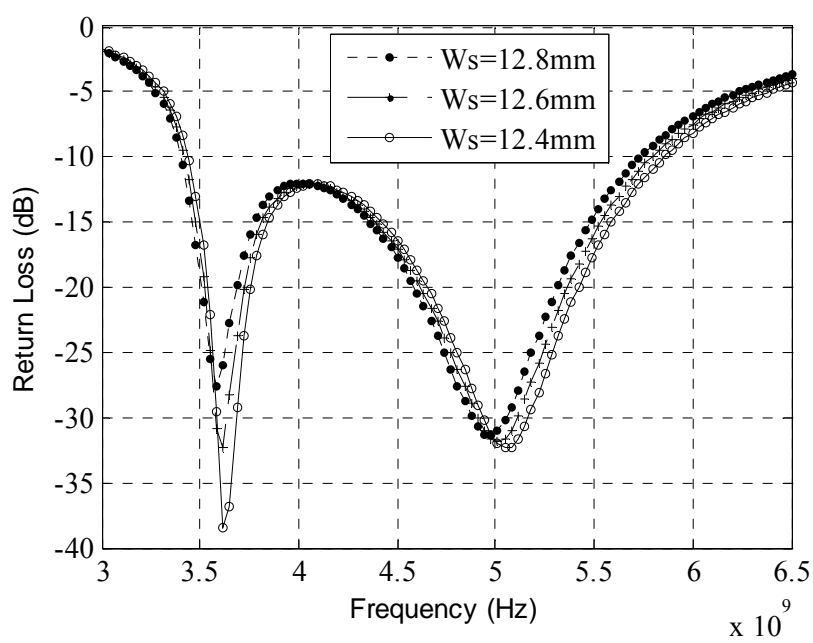

(d) 


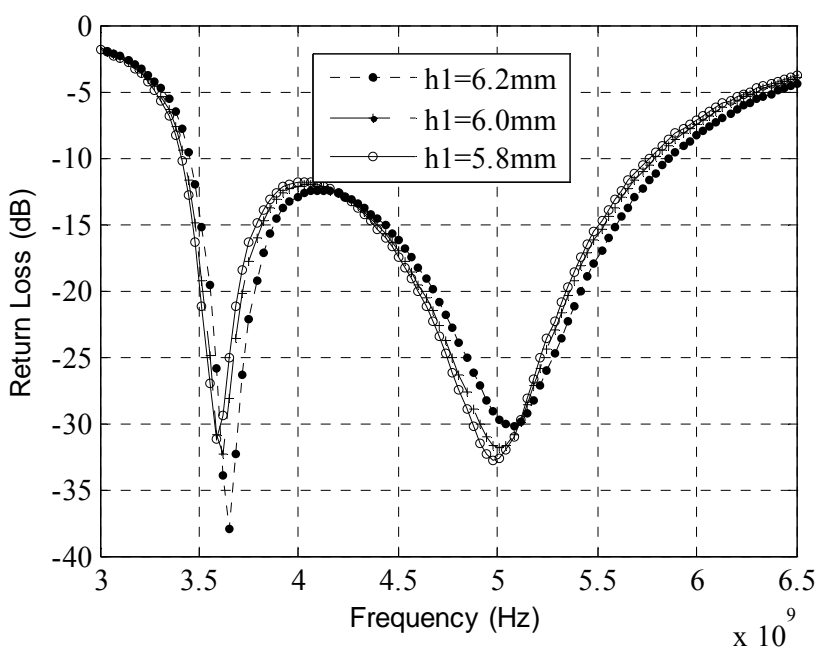

(e)

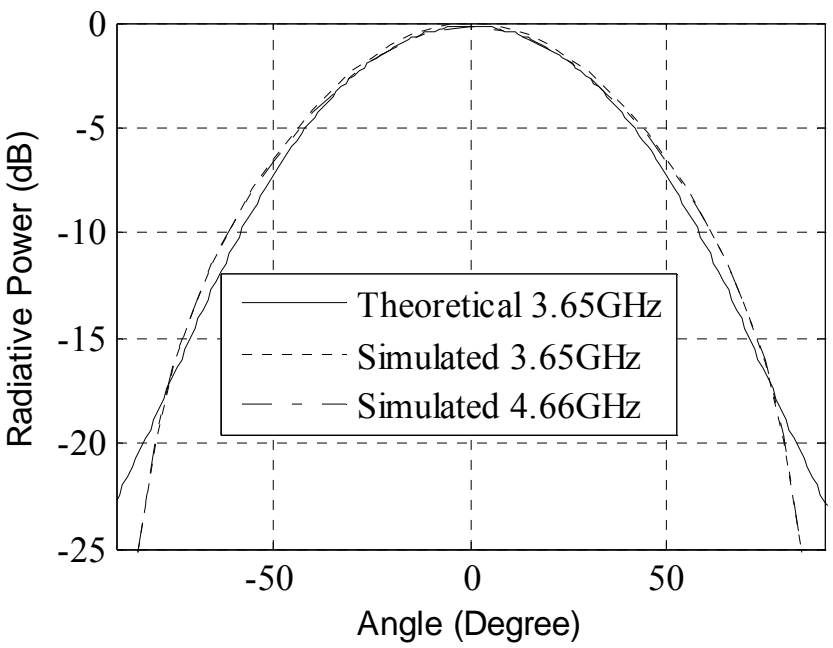

(f)

Figure 4. (a)Variation of return loss with frequency for optimized antenna structure (b)Variation of return loss with frequency for different slot width in lower U-slot loaded patch (c) Variation of return loss with frequency for different slot length (side arm) in lower U-slot loaded patch (d) Variation of return loss with frequency for different slot length (base arm) in lower U-slot loaded patch (e) Variation of return loss with frequency for different thickness between ground and lower patch and (f) Radiation Pattern

\section{Conclusions}

It is concluded that the designed antennas exhibit wideband operation due to dual resonance nature. The U-slot loaded patch when stacked with horizontal slot loaded rectangular patch provides bandwidth enhancement. The resonance operation depends on substrate thickness and slot parameters. The impedance bandwidth of $54.6 \%$ is obtained with optimum design parameters. The half power beamwidth is found to be approximately $68^{\circ}$ and radiation pattern is found to be almost invariant throughout the entire bandwidth.

\section{References}

Ansari J.A. and Ram R.B. 2008. Analysis of Broadband U-Slot Microstrip Patch Antenna. Microwave \& Optical Technology Letters, Vol.50, No.4, pp.1069-1073.

Ansari J.A., Ram R.B. and Singh P. 2008. Analysis of a Gap Coupled Stacked Annular Ring Microstrip Antenna. Progress in Electromagnetic Research PIER B, Vol.4, pp.147-158.

Ansari J.A., Singh P. and Dubey S.K., 2008. H-Shaped Stacked Patch Antenna for Dual-band Operation. Progress in

Electromagnetic Research B, Vol.5, pp. 291-302.

Ansari J.A. and Ram R.B. 2008. Broadband Stacked U-Slot Microstrip Patch Antenna. Progress in Electromagnetic Research PIER Letters, Vol.4, pp.17-24.

Bafrooei P.M. and Shafai L. 1999. Characteristics of Single and Double Layer Microstrip Square Ring Antenna. IEEE Trans. Antennas Propagation, Vol.47, No.10, pp.1633-1639.

Balanis C.A. 1997. Antenna theory analysis and design. $2^{\text {nd }}$ ed., Wiley, New York, pp.728-746.

Bahl I. and Bhartiya P. 1980. Microstrip antennas. Artech House, Massachussets, 48-57.

Bahl I. 2003. Lumped elements for RF and microwave circuits. Artech House, Boston, pp. 456-459.

Chen C. H., Tulintseff A. N. and Sorbello R. M. 1984. Broadband Two-Layer Microstrip Antenna. IEEE Trans. Antennas Prop. Soc. Int. Symp. Dig., Vol.22, pp.251-254.

Garg R. and Bahl I.J. 1978. Microstrip Discontinuities. Int. J. Electronics, 45, pp. 81-87.

Hoefer J. R.Wolfgang 1997. Equivalent series inductivity of a narrow transverse slit in microstrip. IEEE Trans. Microw.

Theory Tech. (USA), Vol. 25,pp. 822-827.

Kumar G. and Gupta K. C. 1984. Broadband Microstrip Antennas using Additional Resonators Gap Coupled to the Radiating Edges. IEEE. Trans. Antennas Propagation, Vol.32, No.12, pp.1375-1379.

Sabban A. 1983. A New Broadband Stacked Two Layered Microstrip Antenna. IEEE Trans. Antennas Propag. Soc. Int. Symp. Dig. Vol.21, pp.63-66.

Svacina J. 1992. Analysis of Multilayer Microstrip Lines by a Conformal Mapping Method. IEEE Trans. Microwave Th. and Techniques, Vol.40, No.4, pp.769-772. 


\section{Biographical notes}

Dr. D.K.Srivastava is a Reader in the Department of Electronics and Communication Engineering, Bundelkhand Institute of Engineering and Technology Jhansi, India. He has more than 14 years of experience in teaching, research and administrative work. His current area of research includes Microwaves and Optical communication. He has published around five papers in referred international journals. He has also presented more than twenty research articles in national and international conferences. He is Member IEEE.

Dr. J. P. Saini is a Professor in the Department of Electronics and Communication Engineering, Bundelkhand Institute of Engineering and Technology Jhansi, India. He has more than 25 years of experience in teaching, research and administrative work. His current area of research includes Multi-criteria Decision-Making, Neural Networks, and Optical and photonic waveguides. He has published more than twenty papers in referred international journals. He has also presented nearly fifty research articles in national and international conferences. He is currently working as a Principal of Madan Mohan Malaviya Engineering College, Gorakhpur, India on deputation. He is life Member IETE and ISTE and Member IEEE(Ex.).

Dr. D.S. Chauhan is Vice Chancellor of Uttarakhand Technical University, Dehradun, India. His teaching profession started at Banaras Hindu University, Varanasi. He has vast experience of teaching, research and administrative work. He has been director of KNIT sultanpur and founder vice Chancellor of U.P.Tech. University, Vice-Chancellor of Lovely Profession University and Jaypee University of Information Technology. He has supervised 17 Ph.D., one D.Sc and currently guiding 8 research scholars. He has authored two books and published and presented 150 research papers in international journals and international conferences. He has delivered hundreds of lectures in USA and Canadian universities and visited half dozen countries in Europe and Asian continent. He is Fellow of institution of Engineers and Member IEEE.

Received January 2011

Accepted March 2011

Final acceptance in revised form April 2011 